\title{
A Comparison of Separators vs. Membranes in Nonaqueous Redox Flow Battery Electrolytes Containing Small Molecule Active Materials
}

Zhiming Liang, ${ }^{1}$ N. Harsha Attanayake, ${ }^{1}$ Katharine V. Greco, ${ }^{2}$ Bertrand J. Neyhouse, ${ }^{2}$ John L. Barton, ${ }^{2}$ Aman Preet Kaur, ${ }^{1}$ William L. Eubanks, ${ }^{1}$ Fikile R. Brushett, ${ }^{*}{ }^{\star}$ James Landon, ${ }^{3,4^{*}}$ and Susan A. Odom ${ }^{1 *}$

1 Department of Chemistry, University of Kentucky, Lexington, KY 40506, USA

2 Department of Chemical Engineering, Massachusetts Institute of Technology, Cambridge, MA 02139, USA

${ }^{3}$ Center for Applied Energy Research, University of Kentucky, Lexington, KY 40511, USA

4 Department of Chemical and Materials Engineering, University of Kentucky, Lexington, KY 40506, USA

Corresponding authors: brushett@mit.edu, james.landon@uky.edu, susan.odom@uky.edu

\section{Summary}

The lack of suitable membranes for nonaqueous electrolytes limits cell capacity and cycle lifetime in organic redox flow cells. Using soluble, stable materials, we sought to compare the best performance that could be achieved with commercially available microporous separators and ionselective membranes. We use organic species with proven stability to avoid deconvoluting capacity fade due to crossover and/or cell imbalance from materials degradation. We found a trade-off between lifetime and coulombic efficiency: non-selective separators achieve more stable performance but suffer from low coulombic efficiencies, while ion-selective membranes achieve high coulombic efficiencies but experience capacity loss over time. When electrolytes are premixed prior to cycling, coulombic efficiency remains high, but capacity is lost due to cell imbalance, which can be recovered by electrolyte rebalancing. The results of this study highlight the potential for gains in nonaqueous cell performance that may be enabled by suitable membranes.

Keywords: Redox flow battery, separator, membrane, crossover, organic electrolyte

\section{Introduction}

Redox flow batteries (RFBs) are promising electrochemical energy storage systems for stationary applications due to their lower capital cost and increased stability compared to other technologies. ${ }^{1}$ In RFBs, electrolyte solutions contain dissolved redox couples that accept or donate electrons during charging and discharging while supporting salt ions migrate between electrolytes to maintain electroneutrality. The effective separation of positive and negative active materials is critical to maximizing capacity in these systems.

To retain high capacities and prevent coulombic efficiency losses due to self-discharge, supporting salt ion transport across a membrane separating the electrolytes must be facile while, at the same time, the crossover of active (charge-storing) materials must be prevented. ${ }^{2-4}$ In commercial vanadium RFBs (VRFBs), which contain highly acidic electrolytes, the most commonly used membrane is Nafion, a perfluorinated sulfonic acid cation exchange membrane. ${ }^{5-}$ 7 Originally developed as a proton exchange membrane for fuel cells, the high proton conductivity, mechanical strength, and chemical stability of Nafion render it one of the best performing membranes for VRFBs. ${ }^{8-11}$ However, at present, there is no commercial Nafion equivalent for 
nonaqueous electrolytes that could be considered state-of-the-art, which is one of the primary reasons that the performance of nonaqueous flow batteries drastically lags that of its aqueous counterparts. ${ }^{3,12-13}$

The lack of well-studied membranes presents a challenge for those developing new active materials due to the difficulty in deconvoluting causes of capacity fade within a cycling cell.5, 14-15 For example, in a separated cell-meaning one in which the positive and negative electrolytes only contain the positive and negative active species-capacity fade due to crossover can dominate performance evaluations during cell cycling. In this situation, one must conduct further analysis (e.g. voltammetry and spectroscopy of each solution) in order to determine whether capacity was lost via active material decomposition and/or crossover. ${ }^{18-20}$ An approach to minimize crossover-driven capacity losses is pre-mixing positive and negative active materials in both electrolytes. This reduces concentration-gradient-driven crossover and enables the use nonselective separators. ${ }^{21-22}$ In an ideal case, cells start with a $50 \%$ capacity reduction and thus data interpretation is more straightforward, as the capacity loss is expected to be the result of materials decomposition. ${ }^{5,16-17}$ However, performance fade can still result from self-discharge, species concentration imbalance, and volumetric (pressure-driven) imbalance. ${ }^{23-24}$ As such it is desirable to investigate capacity fade in pre-mixed electrolytes with stable active species.

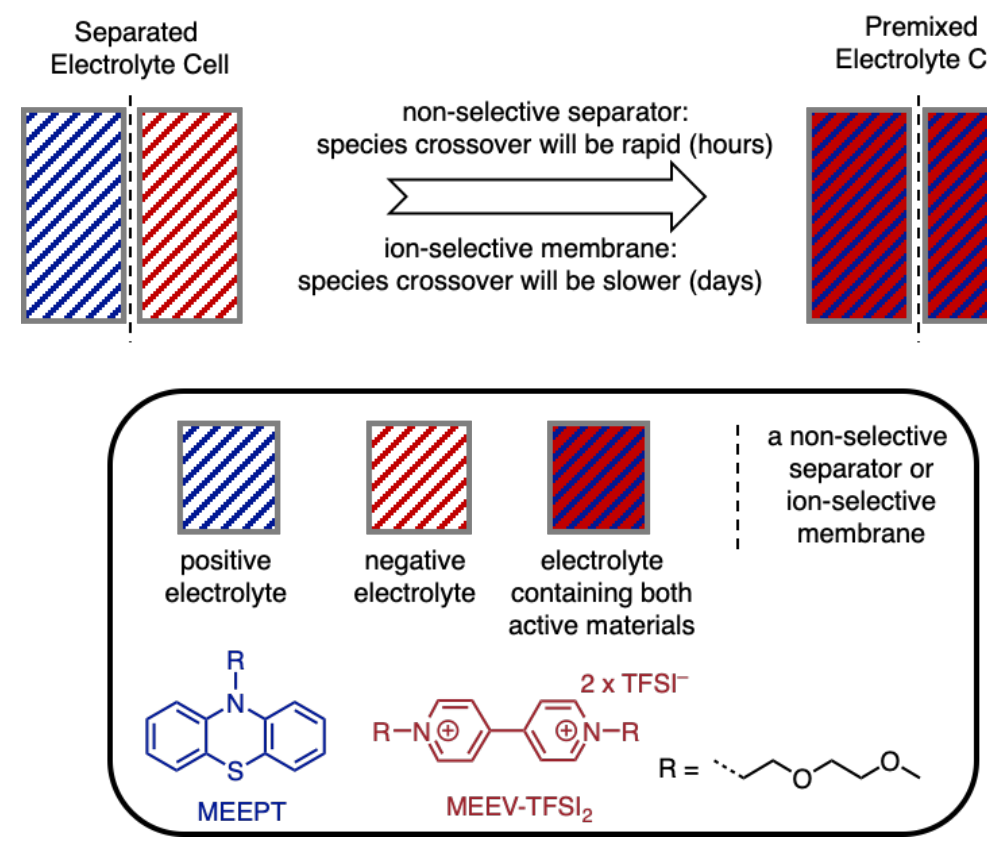

Figure 1. Top: schematic illustrating a liquid cell containing separated positive and negative materials vs. a cell containing pre-mixed electrolytes. Assuming the same total amount of active materials is present in both cells, the pre-mixed electrolyte cell operates at $50 \%$ of the separated cell, but over time, even the once separated cell loses $50 \%$ of its capacity as species crossover occurs. Bottom: a representation of the chemical structures of the active materials used in this study.

A challenge in screening membranes and separators for nonaqueous electrolytes is presented by the limited number of organic active materials that are both stable and soluble at all relevant states of charge. ${ }^{25-29}$ While several research groups have reported high stability and high solubilities of active materials, their studies usually provide solubility values for the uncharged forms of the organic species, but often do not also include the isolation and analysis of the charged forms of active species. ${ }^{22,}$ 30-32 Without knowing the solubility of both the oxidized and reduced 
species, the upper limit in active materials concentration cannot be determined prior to cycling. However, with a few exceptions, the concentrations used for cycling are usually sufficiently low $(10-50 \mathrm{mM})$ that limitations in charged state solubility are not observed. Only in a few cases have flow cells been reported with relatively high concentrations of active materials $(>0.1 \mathrm{M})$, and these studies did not focus on the effect of crossover or crossover prevention. ${ }^{22,29,31-34}$

We recently developed organic active materials (i.e. $\mathrm{N}$-[2-(2-methoxyethoxy)ethyl]phenothiazine (MEEPT)) with high stability and high solubility, and showed no measurable capacity fade due to decomposition after being cycled at relatively high concentrations $(0.3$ to $0.4 \mathrm{M}) .{ }^{29,35}$ It is worth noting that these materials are stable in the chemical and potential window and with respect to each other, which enables pre-mixing of the electrolytes. To evaluate the effect of crossover, premixing, and separator choice on NAqRFB performance, we sought to analyze their performance in full cells, both separated and pre-mixed, with select commercially available membranes and separators. We are interested in the performance of ion-selective membranes to determine which - if any - would prevent active materials from crossing over, and to compare the performance trade-off of capacity fade and coulombic efficiency of membrane-containing cells to those containing non-selective separators alongside pre-mixed negative and positive materials.

In this study, we report the utilization of the positive active material $N$-[2-(2methoxyethoxy)ethyl]phenothiazine (MEEPT) ${ }^{29}$ and the negative active material bis[2-(2methoxyethoxy)ethyl]viologen bis(trifluoromethanesulfonyl)imide (MEEV-TFSI ${ }^{35}$ (Figure 1) in nonaqueous electrolytes for RFBs. First, we screened the ionic conductivity and reversibility of both species' redox processes in a variety of supporting electrolytes and downselected based on optimal performance metrics. With a chosen supporting electrolyte, we monitored the crossover of active materials in $\mathrm{H}$-cell setups and down-selected candidate membranes and separators. Subsequently, we measured flow cell impedance to identify an optimal ion-exchange membrane, which we compared with a more conductive commercial microporous separator. Finally, in flow cells containing pre-mixed electrolytes, we cycled full cells with a microporous polymer separator between each electrolyte reservoir - both at low $(0.1 \mathrm{M})$ and moderate $(0.5 \mathrm{M})$ concentrations of active materials. Here we report the results of these experiments and compare provide guidance on how these separator materials should be implemented for best performance.

\section{Results and Discussion}

\section{Cyclic Voltammetry and lonic Conductivity}

After determining that the redox-active materials were stable in each other's presence (see cyclic voltammograms of both materials together in Figure S1), the first step in screening materials for flow batteries was to determine which electrolyte to employ in flow cells. In an ideal RFB electrolyte, the redox events are reversible, diffusion coefficients are large, active species solubilities are high, and solutions exhibit high ionic conductivities - each of these properties is affected not by the active species itself, but by the choice of supporting salt and electrolyte. . $^{2} 36$ To determine which supporting electrolytes exhibited these properties, we studied several combinations of electrolytes, measuring solution conductivities, characterizing reversibility, and measuring diffusion coefficients of the active species using variable scan rate cyclic voltammetry (CV). Unlike MEEV-TFSI 2 , which has two reversible redox events, MEEPT exhibits only one reversible redox event, so we decided to access one redox event in both active materials in flow cell cycling such that equimolar concentrations could be employed. Specifically, we focused our analysis on the first oxidation of the positive active material, MEEPT, and the first reduction of the negative active material, MEEV-TFSI 2 . We selected acetonitrile (ACN), propylene carbonate (PC), and dimethoxyethane (DME) as polar aprotic solvents, each containing $0.5 \mathrm{M}$ lithium 
tetrafluoroborate $\quad\left(\mathrm{LiBF}_{4}\right), \quad$ lithium hexafluorophosphate $\left(\mathrm{LiPF}_{6}\right)$, lithium bis(trifluoromethyl)sulfonimide (LiTFSI), or tetraethylammonium tetrafluoroborate $\left(\mathrm{TEABF}_{4}\right)$ as supporting salts.

Table S1 summarizes the results of variable scan rate CV, with voltammograms and RandlesSevcik plots in Figures S2-S7. The redox potentials, which were referenced to ferrocene/ferrocenium $\left(\mathrm{Cp}_{2} \mathrm{Fe}^{0 /+}\right)$ at $0 \mathrm{~V}$, showed little variation from one electrolyte to another, with values ranging from $-0.79 \mathrm{~V}$ to $-0.85 \mathrm{~V}$ vs. $\mathrm{Cp}_{2} \mathrm{Fe}$ for $\mathrm{MEEV}-\mathrm{TFSI}{ }_{2}$ and $0.30 \mathrm{~V}$ to $0.34 \mathrm{~V}$ vs. $\mathrm{Cp}_{2} \mathrm{Fe}^{+/ 0}$ for MEEPT. Peak current ratios and peak to peak separations, which are used to estimate active species reversibility, are largely similar for each species, with ratios ranging from 1.03 to 1.34 for MEEV-TFSI 2 and 1.02 to 1.11 for MEEPT, and peak separations ranging from 59 to $64 \mathrm{mV}$ for both active species. The diffusion coefficients estimated by Randles-Sevcik analysis, however, exhibited large differences among the tested electrolytes, with the average diffusion coefficients being ca. 5x larger in ACN than in PC. This observation is in agreement with the Stokes-Einstein relationship, which describes an inverse proportionality between diffusion coefficient and solution viscosity. At $20^{\circ} \mathrm{C}$, the viscosities of $\mathrm{ACN}, \mathrm{PC}$, and DME are $0.36,2.47$ and $0.42 \mathrm{mPa} \bullet \mathrm{s}$, respectively. ${ }^{37,38-39}$

As both active species present similar reversibility in all electrolytes tested, we focused on diffusivity and ionic conductivity as the main criterion for selection of the electrolyte to use in flow cells. Ionic conductivities, which were measured using a thermal conductivity cell, are summarized in Table S3, with standard deviations provided. The average ionic conductivities of electrolyte salts in ACN are much larger than in PC (up to 10x) and DME (up to 3x) (See Table S2). At 39.10 $\mathrm{mS} \mathrm{cm}{ }^{-1}, \mathrm{ACN}$ containing $0.5 \mathrm{M} \mathrm{TEABF}_{4}$ exhibited the highest ionic conductivity in addition to some of the highest diffusion coefficients for MEEPT and MEEV-TFSI ${ }_{2}$, making it the electrolyte of choice for further studies.

\section{Screening Membranes and Separators for Crossover and Resistance}

For NAqRFBs, membranes and separators play a critical role in performance, as they should (i) prevent active species from exchanging between the negative and positive sides, (ii) offer high conductivity and low ohmic resistance, and (iii) be inert to reaction with the electrolyte materials. Preventing crossover of active species is important for retaining capacity and preventing selfdischarge. The ionic conductivity and thickness of membranes and separators dictate ohmic losses in electrochemical cells which, in turn, determine the upper limits for charging and discharging rates. Reactions of the membrane with electrolyte components limit capacity due to materials loss and can foul the membrane, increasing impedance, thus preventing facile charge and discharge.

To identify the best-performing membranes, i.e. membranes that limit crossover of active species, we used stationary $\mathrm{H}$-cells to examine crossover in a series of commercial cation exchange membranes (CEMs), anion exchange membranes (AEMs), and separators, which were all used as received following soaking in the electrolyte solution for the membranes. For the preliminary measurements, we observed crossover visually, assembling $\mathrm{H}$-cells and filling each side with 0.5 $\mathrm{M} \mathrm{TEABF}_{4} / \mathrm{ACN}$ electrolyte and MEEPT at $25 \mathrm{mM}$; we chose to analyze MEEPT visually because, although it is colorless, the addition of $\mathrm{NOBF}_{4}$ results in an intense coloration of the solution. Photographs recorded $12 \mathrm{~h}$ after addition of MEEPT to the $\mathrm{H}$-cell, with $\mathrm{NOBF}_{4}$ added for visualization, are shown in Figure S9. Neosepta AMX and AHA (AEMs), Nafion 117 (CEM), FAPQ 375 PP (AEM), and Dow YMNF 3001 (XEM) showed the lowest crossover. From the results of these crossover screening tests, Neosepta AMX and AHA, one or two layers of FAPQ 375 PP, and Nafion 117 were considered as candidate membranes for MEEPT/MEEV-TFSI ${ }_{2}$ full cell 
cycling. Daramic 175, a commonly employed battery separator, was chosen as a microporous polymer separator.

Next, ohmic resistance was used to both narrow membrane selection as well as to estimate the necessary time for equilibration. To measure ohmic resistance, we assembled flow cells containing each membrane or separator and recorded the high frequency intercept of the electrochemical impedance (ohmic resistance) vs. time as $0.5 \mathrm{M}$ TEABF $/$ ACN was pumped through the cell at $10 \mathrm{~mL} / \mathrm{min}$. For FAPQ, multiple membranes were stacked, as layering the membranes or separators is a demonstrated method to decrease the active species crossover rate. ${ }^{3,40}$ Figure 2a shows the results for the Daramic separator and the Nafion 117 and FAPQ 375 membranes, which displayed the lowest values for resistance. For the Daramic 175 separator, the resistance started and stayed at ca. $3 \Omega \mathrm{cm}^{2}$ for the duration of the test. For the FAPQ 375 PP membrane, the ohmic resistance leveled out to ca. $14 \Omega \mathrm{cm}^{2}$ (one layer) and ca. $24 \Omega \mathrm{cm}^{2}$ (two layers) after $5 \mathrm{~h}$ of exposure in the flow cell. Similar to FAPQ 375 PP, the Nafion 117 membrane yielded a resistance ca. $16 \Omega \mathrm{cm}^{2}$ within a few hours. However, for Neosepta AMX and AHA, the ohmic resistance leveled out at $200 \Omega \mathrm{cm}^{2}$ even after ca. 20 and $10 \mathrm{~h}$, respectively (Figure S8). These high resistances would require unacceptably low cycling current densities, and thus, Neosepta membranes were eliminated from further study.
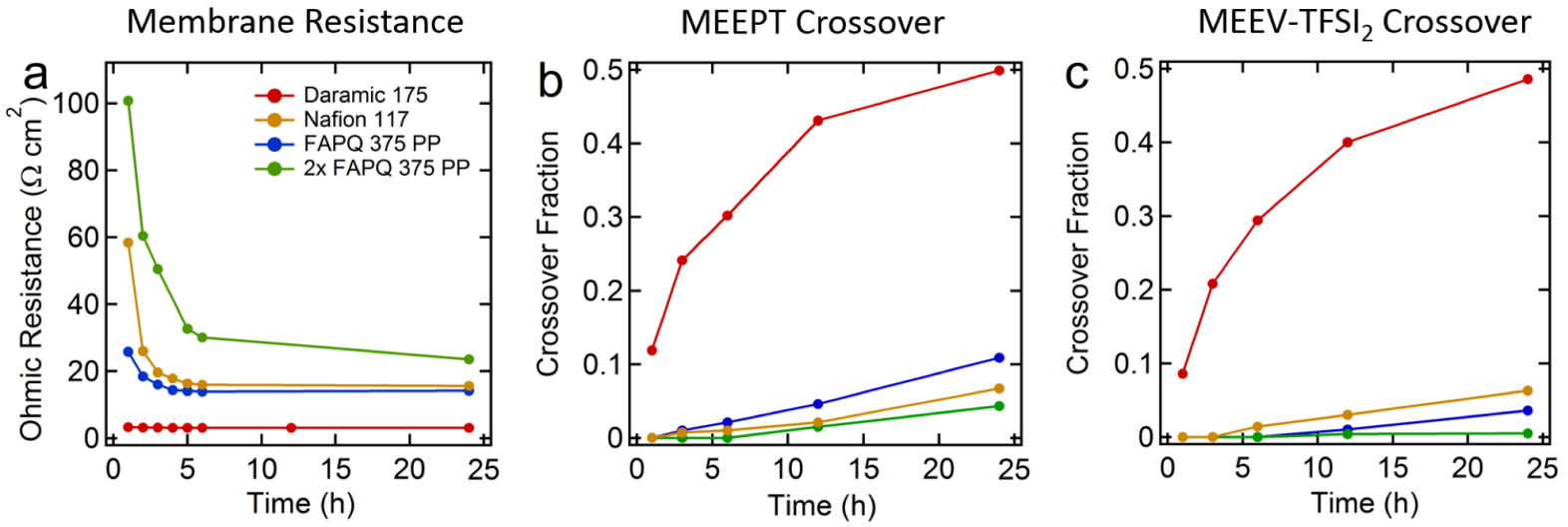

Figure 2. A comparison of membrane resistance (a), MEEPT crossover (b), and MEEV-TFSI ${ }_{2}$ crossover (c) vs. time in $0.5 \mathrm{M} \mathrm{TEABF}_{4} / \mathrm{ACN}$.

For the down-selected membranes and the microporous polymer separator, we further analyzed crossover - this time more quantitatively - using CV to monitor species concentration in both halfcells. This experiment gives us an idea of what to expect for whether separating (vs. pre-mixing) the negative and positive active materials would be worthwhile. Here, $\mathrm{H}$-cells were again assembled with the membrane or separator of interest, with both sides containing $0.5 \mathrm{M}$ $\mathrm{TEABF}_{4} / \mathrm{ACN}$, and - additionally - one side containing $0.2 \mathrm{M}$ of MEEV-TFSI 2 or MEEPT. Figure S10 shows the crossover of MEEV-TFSI 2 and MEEPT for up to $24 \mathrm{~h}$ for Daramic 175 (separator), Nafion 117 (the CEM), and one or two-layers FAPQ 375 PP (the AEM).

The crossover fraction, defined as the permeate concentration divided by the net concentration of both sides of the $\mathrm{H}$-cell, increases with time until each side reaches a uniform concentration; in such a test, the maximum value of any material evaluated is 0.5 . The crossover fraction for both MEEPT (Figure 2b) and MEEV-TFSI 2 (Figure 2c) increased with time. The crossover fraction with 
the Daramic 175 separator reached equilibrium after $12 \mathrm{~h}(\sim 50 \%$ in both sides of the H-cell). The crossover in each chamber when using ion exchange membranes is below $10 \%$ after $24 \mathrm{~h}$. This follows our expectations, as the crossover rate should be slower for ion exchange membranes in their uncharged (MEEV-TFSI ${ }_{2}$ ) and for charged (both) species due to them being positively charged. The crossover fraction for two layers of FAPQ 375 PP is ca. 1/2 that compared to one layer of FAPQ $375 \mathrm{PP}$ for both active materials after $24 \mathrm{~h}$. The crossover fraction for Nafion 117 is higher than the FAPQ 375 PP membrane, especially for MEEV-TFSI ${ }_{2}$ which is up to $8 x$ higher (due to MEEV ${ }^{2+}$ having a higher charge than neutral MEEPT). In addition, for MEEPT/ MEEV$\mathrm{TFSI}_{2}$ full cell cycling, where both charged active materials are in cationic (radical) states, Nafion 117 may better facilitate cation active species crossover. Therefore, the Daramic 175 separator and FAPQ 375 PP AEM were selected for full cell testing.

\section{Full Flow Cell Cycling}

We tested three $0.5 \mathrm{M}$ MEEPT/MEEV-TFSI ${ }_{2}$ flow cells: (i) pre-mixed loading with a Daramic 175 separator; (ii) pre-mixed loading with one FAPQ 375 PP membrane; and (iii) separated loading with two FAPQ 375 PP membranes. While in theory additional FAPQ 375 PP membranes could be added to further reduce capacity fade, we limited ourselves to two such that we maintain relatively low ohmic resistances and reasonable voltaic efficiency (VE). Before running these cells, we performed rate cycling studies to determine the current density to use in cell cycling as shown in Figure 3. Constant current cycling with the Daramic 175 separator was conducted at current densities of $5,10,15,20$, and $30 \mathrm{~mA} \mathrm{~cm}^{-2}$, resulting in discharge capacities of $64.6 \%, 77.8 \%$, $77.0 \%, 76.4 \%$, and $70.4 \%$, respectively, of the theoretical value (13.4 $\mathrm{Ah} \mathrm{L}^{-1}$ or $134 \mathrm{mAh}$ ). The constant current cycling of a full cell with FAPQ 375 PP was conducted at current densities of 5 , 10,15 , and $20 \mathrm{~mA} \mathrm{~cm}^{-2}$, resulting in discharge capacities of $93.3 \%, 87.3 \%, 73.6 \%$, and $33.7 \%$ of the theoretical value (13.4 $\mathrm{Ah} \mathrm{L}^{-1}$ or $134 \mathrm{mAh}$ ). For the full cell with 2x FAPQ $375 \mathrm{PP}$, constant current cycling was conducted at current densities of $5,10,15$, and $20 \mathrm{~mA} \mathrm{~cm}^{-2}$, resulting in discharge capacities of $85.4 \%, 69.9 \%, 51.8 \%$, and $14.9 \%$ of the theoretical value (13.4 $\mathrm{Ah} \mathrm{L}^{-1}$ or $134 \mathrm{mAh}$ ). Note that in both cases with FAPQ, we did not access $30 \mathrm{~mA} \mathrm{~cm}^{-2}$ due to the dramatic drop in capacity from 10 to $20 \mathrm{~mA} \mathrm{~cm}^{-2}$ due to unacceptably high ohmic resistance. As expected, the accessed capacities should decrease as the current density increases due to larger cell polarization. However, capacities of the cell assembled with the Daramic 175 separator at $5 \mathrm{~mA}$ $\mathrm{cm}^{-2}$ are unusual. The charge capacity rose to $33 \mathrm{Ah} \mathrm{L}^{-1}$, which is $2.5 \mathrm{x}$ higher than its theoretical value (13.4 $\mathrm{Ah} \mathrm{L}^{-1}$ ), while, at the same time, the average discharge capacity decreased to $8.7 \mathrm{Ah}$ $\mathrm{L}^{-1}$ which is only ca. $65 \%$ of the theoretical value and is lower than capacities accessed at other higher current densities. This phenomenon may likely be caused by crossover-induced selfdischarge of the active materials - lower current densities require a longer cycling time, which accentuates crossover rates relative to the charging rate, resulting in a more pronounced effect of self-discharge reactions. 

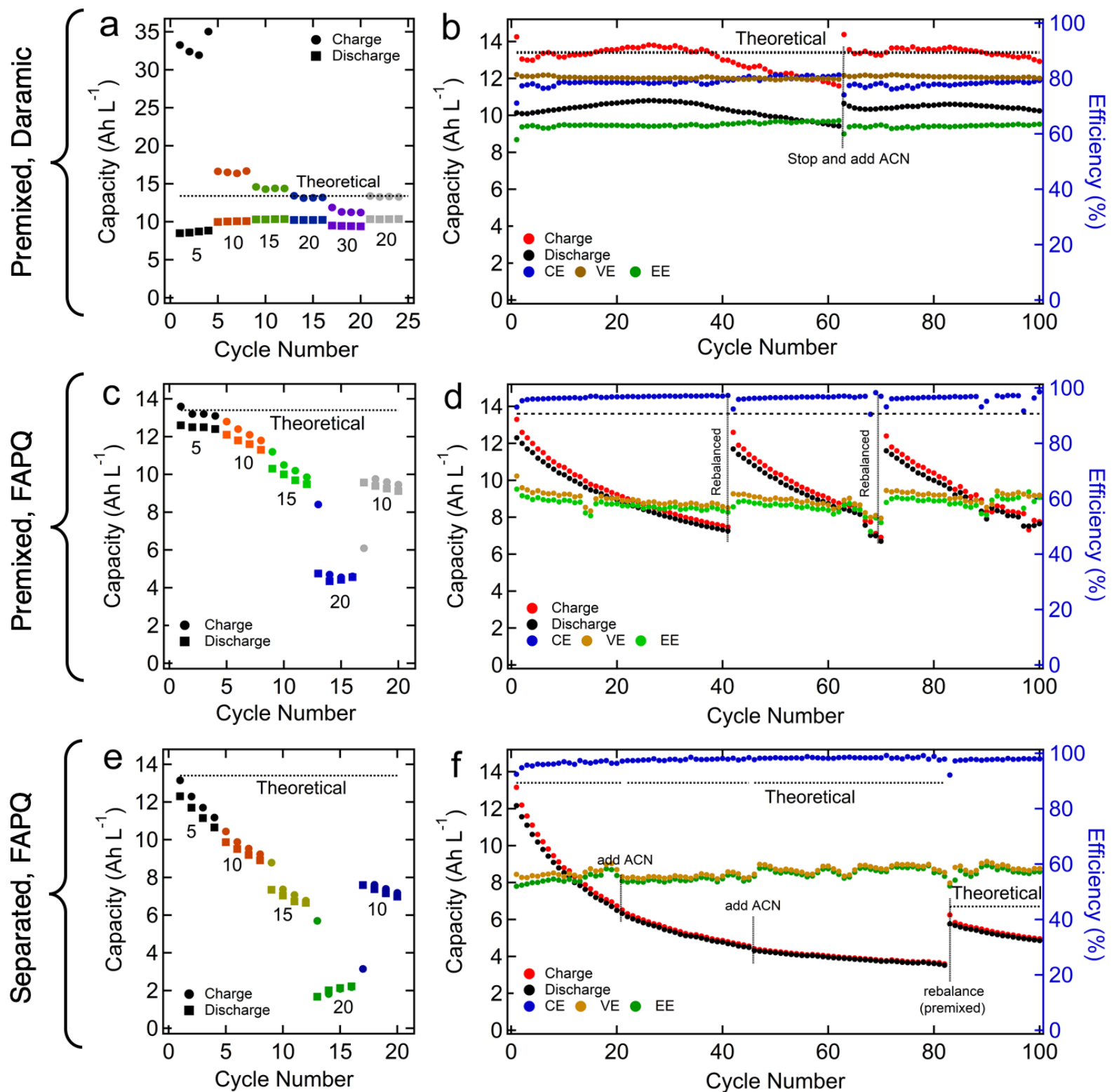

Figure 3. Rate study of $0.5 \mathrm{M}$ MEEPT/MEEV-TFSI 2 redox flow cells assembled with Daramic 175, pre-mixed electrolytes (a), with 1x FAPQ 375 PP pre-mixed electrolytes (c), and with 2x FAPQ 375 PP, separated electrolytes (e). Cycling results of the Daramic 175 cell with constant current $20 \mathrm{~mA} \mathrm{~cm}^{-2}(\mathrm{~b})$, the FAPQ $375 \mathrm{PP}$ cell with constant current $10 \mathrm{~mA} \mathrm{~cm}^{-2}(\mathrm{~d})$, and the 2x FAPQ $375 \mathrm{PP}$ cell with constant current $10 \mathrm{~mA} \mathrm{~cm}^{-2}$ (f). For $3 b, 3 \mathrm{~d}$, and $3 \mathrm{f}$, the rate study was conducted as previously described. The theoretical capacity of $0.5 \mathrm{M}$ pre-mixed or separated cell is $13.4 \mathrm{Ah}$ $\mathrm{L}^{-1}$ (134 $\mathrm{mAh}$ ). During the cell cycling studies, due to the volatility of $\mathrm{ACN}, \mathrm{ACN}$ was added in the pre-mixed cell with Daramic 175 (b) at cycle $61(\sim 285 \mathrm{~h}$; the cell was stopped for $5 \mathrm{~h}$ after adding ACN and before continuing charge/discharge). The pre-mixed cell with FAPQ 375 PP (d) was rebalanced at cycle $41(\sim 300 \mathrm{~h})$ and $70(\sim 215 \mathrm{~h})$. For the separated cell with 2X FAPQ $375 \mathrm{PP}$ (f), ACN was added at cycles $21(\sim 166 \mathrm{~h})$ and $45(\sim 284 \mathrm{~h})$. At cycle $83(\sim 410 \mathrm{~h})$, the posolyte and negolyte were rebalanced. The total run time to access 100 cycles was $\sim 470,750$, and 500 $\mathrm{h}$ for the cells in (b), (d), and (f), respectively. 
Considering the time and fraction of accessed capacities for each cycle in the balanced experiment, 20,10, and $10 \mathrm{~mA} \mathrm{~cm}^{-2}$ were chosen as the current densities for cells with Daramic 175, FAPQ 375 PP, and 2x FAPQ 375 PP, respectively. The cycling results are shown in Figure $3 a$ and $3 b$ (Daramic 175), 3c and 3d (FAPQ 375 PP), and $3 e$ and $3 f$ (2x FAPQ 375 PP). For the cell assembled with the Daramic 175 separator, the charge/discharge capacities remained relatively stable for the first 35 cycles. After 35 cycles the capacity began to fade $(\sim 0.12 \mathrm{mAh}$ per cycle as shown in Table 1), but the charge/discharge capacities recovered to 13.6 and $10.5 \mathrm{Ah} \mathrm{L-}$ 1 , respectively, when $A C N$ was added to correct the volumetric imbalance at cycle 63 . The recovery of capacities by adding $\mathrm{ACN}$ strongly suggests that solvent loss was the major contributor to capacity loss in the Daramic cell. To further prove this hypothesis, we analyzed the cycled solutions by CV-as Figure S14 shows, the concentration of the posolyte and negolyte increased from cycle 62 to cycle 100 due to the evaporation of ACN, which resulted in decreased electrolyte volume. The unbalanced volume and concentration can lead to capacity limitations, controlled by one chamber's active species concentration, either oxidation or reduction limitations.

For the pre-mixed cell assembled with FAPQ 375 PP, we observed rapid capacity fade (Figure 3b). This capacity loss is likely connected to the concentration gradient measured at cycles 41 and 70 (Figure S14), which was corrected by rebalancing the flow cell at cycles 42 and 71, resulting in discharge capacities recovered to 11.7 and $11.6 \mathrm{Ah} \mathrm{L}^{-1}$ compared to the theoretical 13.6 Ah $\mathrm{L}^{-1}$. The non-selective nature of Daramic allows active species to cross and re-cross the separator more freely, resulting in limited concentration imbalances alongside low coulombic efficiency. Conversely, FAPQ 375 PP is more selective, maintaining much higher coulombic efficiency ( 96\%) but suffering capacity fade over time. This counterintuitive loss in performance with a more selective membrane is in agreement with previous results demonstrated by Small et al. in aqueous organic RFBs. ${ }^{30}$ Consistent with their analysis, we offer an explanation of this phenomenon, taking into consideration diffusion and migration fluxes through the membrane. During the charging step, both current and the concentration gradient drive positively charged MEEPT from the positive side to the negative side. However, because MEEPT is neutral on the negative side, the current does not work to rebalance the system during the discharging step, resulting in a net movement of MEEPT to the negative half-cell during cycling. This phenomenon may similarly result in some net movement of MEEV-TFSI ${ }_{2}$, as it is possible that FAPQ-375 PP is ineffective at preventing cation crossover, as has been shown in the crossover tests and for similar anion exchange membranes. ${ }^{41}$ While additional contributions from electroosmotic drag cannot be ignored completely, its relative contribution to the crossover flux is expected to be negligible considering the symmetry of the pre-mixed electrolyte. Taken together, these results highlight the need to consider active species charge in both states when designing separation strategies for organic redox flow cells, this demands a detailed analysis of membrane transport behavior in nonaqueous RFBs to predict cycling performance.

The capacity fade is much faster for the cell with separated electrolytes (assembled with 2x FAPQ 375 PP) than the pre-mixed electrolytes. Similarly, this is due to the combined effects of diffusion, migration, and electroosmotic drag resulting in crossover. ${ }^{42}$ In particular, we observed volume imbalances likely cause by electroosmotic drag, further increasing capacity fade rate. To alleviate this problem, ACN was added to balance the electrolyte volumes at cycle 20 . To determine to what extent the residual capacity fade was due to concentration gradient-driven crossover, we rebalanced the negative and positive electrolytes by mixing the electrolytes at cycle 84 . After rebalancing, the new theoretical capacity $\left(6.7 \mathrm{Ah} \mathrm{L}^{-1}\right)$ is $50 \%$ of the initial value (13.4 $\left.\mathrm{Ah} \mathrm{L}^{-1}\right)$, and the accessed discharge capacity recovered to $5.76 \mathrm{Ah} \mathrm{L}^{-1}$, which is $86.0 \%$ of the theoretic premixed value and $43.0 \%$ of the original value. The accessed capacity recovery of the two cells by 
rebalancing the posolyte and negolyte demonstrates that the two redox active materials MEEPT and $\mathrm{MEEV}-\mathrm{TFSI}_{2}$ are generally robust over long-term cycling.

Table 1. Coulombic efficiency (CE), voltage efficiency (VE), energy efficiency (EE), and capacity retention of $0.5 \mathrm{M}$ MEEPT/MEEV-TFSI 2 full cells with one and two layers of FAPQ 375 PP membrane and the Daramic 175 separator for 100 cycles.

\begin{tabular}{l|c|c|c|c|c}
\hline Membrane or Separator & Electrolytes & CE (\%) & VE (\%) & EE (\%) & $\begin{array}{c}\text { Capacity } \\
\text { Retention (\%) }\end{array}$ \\
\hline Daramic 175 & pre-mixed & $78.5 \pm 1.5$ & $80.4 \pm 0.5$ & $63.1 \pm 0.9$ & $92.9^{\mathrm{a} ;} 96.2^{\mathrm{b}}$ \\
\hline FAPQ 375 PP & pre-mixed & $96.5 \pm 1.4$ & $59.9 \pm 2.1$ & $56.0 \pm 2.1$ & $59.0^{\mathrm{c}} ; 57.3^{\mathrm{d}} ; 65.3^{\mathrm{e}}$ \\
\hline 2x FAPQ 375 PP & separated & $97.7 \pm 1.1$ & $57.1 \pm 1.7$ & $55.7 \pm 1.9$ & $28.9^{f} ; 43.0^{\mathrm{g}}$ \\
\hline
\end{tabular}

Note: a before adding ACN (1-61 cycles); b adding ACN (62-100 cycles); c before re-balancing (1-41 cycles); d re-balanced (42-70 cycles); e re-balanced (71-100 cycles); f before re-balancing (1-83 cycles); 9 rebalanced (84-100 cycles).

To further confirm that the active species were stable during cycling, $\mathrm{CV}$ and ${ }^{1} \mathrm{H}$ NMR spectroscopy were employed after 100 cycles. In voltammograms, all observed redox events match those of the initial solutions, and no new redox active species were found after cycling (Figure 4 and Figure S13). Figure $4 \mathrm{~d}$ shows the ${ }^{1} \mathrm{H}$ NMR spectra of cycled positive and negative electrolytes in $\mathrm{CD}_{3} \mathrm{CN}$. Excess sodium thiosulfate was added to quench residual MEEPT-BF radicals, and the solid was filtered off as well as the solvent evaporated before collecting the ${ }^{1} \mathrm{H}$ NMR spectra. Air was bubbled through the solutions to quench residual reduced viologen radicals. The spectra of the negative electrolyte samples display some peak broadening for the signals corresponding to the 4,4'-bipyridine core and of the methylene groups directly attached to the nitrogen atoms, which we presume is due to the presence of a small amount of reduced viologen. ${ }^{43}$ 


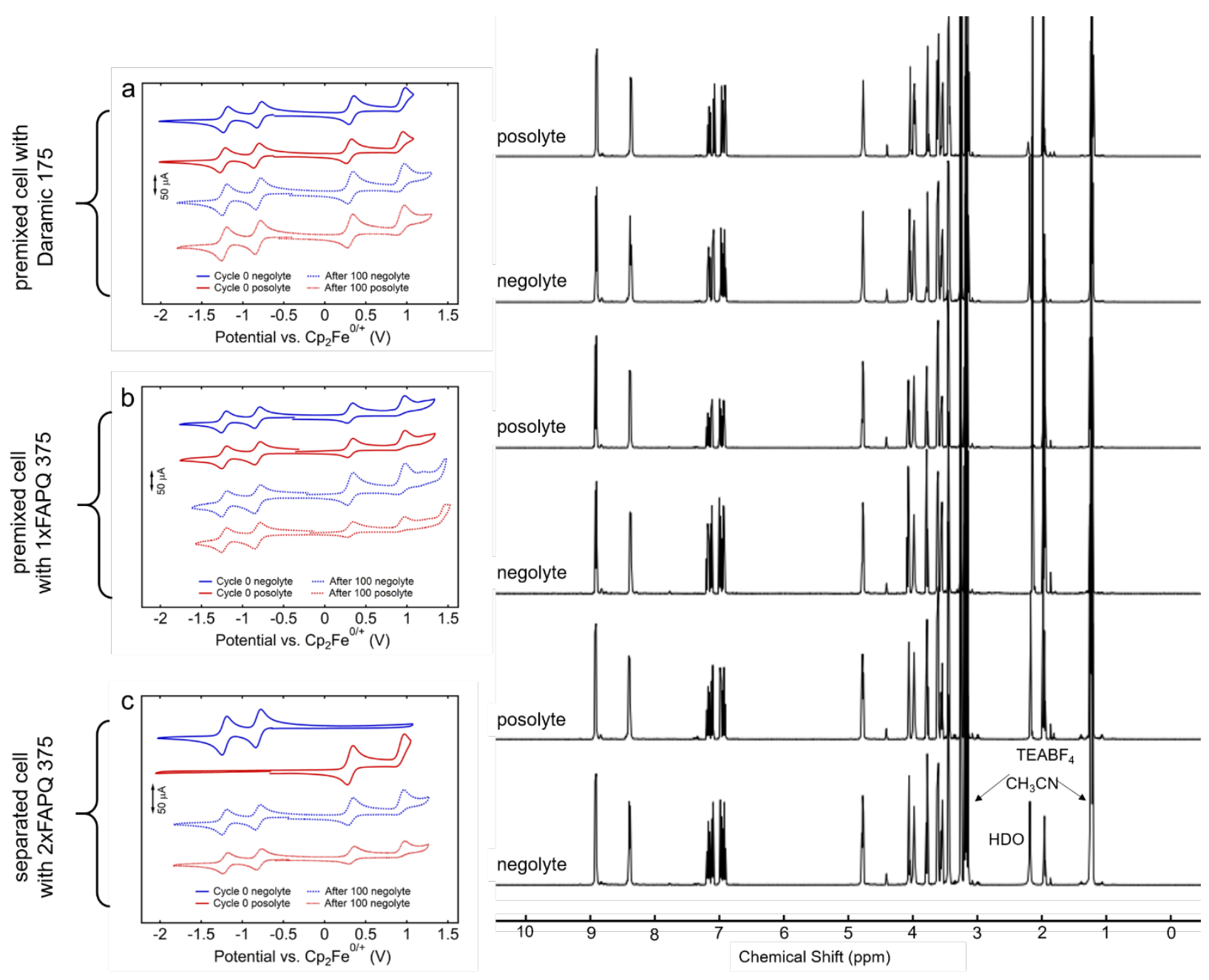

Figure 4. Cyclic voltammograms of posolytes and negolytes with the Daramic 175 separator (a), FAPQ 375 PP (b), and 2x FAPQ 375 PP membranes (c) before and after cycle 100 (potential referenced to $\mathrm{Cp}_{2} \mathrm{Fe}^{0 /+}$ at $0 \mathrm{~V}$ ). The scan rate is $100 \mathrm{mV} \mathrm{s}^{-1}$. d) ${ }^{1} \mathrm{H}$ NMR spectra of active material solutions after 100 cycles $\left(\mathrm{CD}_{3} \mathrm{CN}, 400 \mathrm{MHz}\right)$. from top to bottom: Daramic, posolyte and negolyte solutions; FAPQ 375 PP, posolyte and negolyte solutions; 2x FAPQ 375 PP, posolyte and negolyte solutions.

\section{Conclusions}

Active materials crossover is one of the most challenging problems being faced for NAqRFBs for full cell cycling, as there are currently no state-of-the-art separator materials for these systems. Using commercially available flow cell components and organic materials synthesized using few steps, we tested the performance of NAqRFBs for a full flow cell with MEEPT and MEEV-TFSI 2 electrolytes, with the goal of identifying separators that enable high coulombic efficiency by reducing crossover without unacceptably high ohmic resistance. We also explored the trade-offs between capacity and crossover by comparing systems with fully separated positive and negative electrolytes to those with pre-mixed electrolytes (positive and negative active species are present on both sides of the cell to prevent concentration driven crossover). We found that selective separators (ion-exchange membranes) reduced crossover rates, but also reduced possible 
current densities with acceptably low overpotential. With non-selective separators, the rate of crossover was unacceptably high in systems separated electrolytes; in the pre-mixed system, higher current densities can be realized, but cell capacities are cut in half. Ultimately, this work shows that it is important to consider the crossover rate of all species in solution, both the oxidized and reduced form, when selecting a separator, and that pre-mixed electrolytes may be a viable option for applications that do not require high cell capacity.

\section{Experimental Procedures}

\section{Chemical and Materials Sources}

The following chemicals, their purities, and suppliers are as follows: nitrosonium tetrafluoroborate $\left(\mathrm{NOBF}_{4}, 98 \%\right.$, anhydrous, Alfa Aesar), acetonitrile (ACN, 99.9\%, anhydrous, J.T.Baker), propylene carbonate (PC, 99.7\%, anhydrous, Sigma-Aldrich), 1,2-dimethoxyethane (DME, 99.5\%, anhydrous, Sigma-Aldrich), lithium tetrafluoroborate ( $\mathrm{LiBF}_{4}, 98 \%$, anhydrous, Acros Organics), lithium bis(trifluoromethanesulfonimide) (LiTFSI, 99\%, nitrogen flushed, Acros Organics), lithium hexafluorophosphate $\left(\right.$ LiPF $_{6}$, battery grade, BASF), tetraethylammonium tetrafluoroborate $\left(\mathrm{TEABF}_{4}, 99.9 \%\right.$, BASF), tetraethylammonium bis(trifluoromethylsulfonyl)imide (TEATFSI, > 98\%, lolitec), $\quad \mathrm{N}$-[2-(2-methoxyethoxy)ethyl]phenothiazine (MEEPT, > 98\%, TCl) and bis[2-(2methoxyethoxy)ethyl]viologen bis(trifluoromethanesulfonyl)imide MEEV-TFSI ${ }_{2}$ were synthesized as previously reported. 29,35

${ }^{1} \mathrm{H},{ }^{19} \mathrm{~F}$, and ${ }^{13} \mathrm{C}$ NMR spectra were obtained on a $400 \mathrm{MHz}$ Bruker Avance NEO (equipped with a Smart Probe) in DMSO- $d_{6}$ obtained from Cambridge Isotope Laboratories. For ${ }^{19} \mathrm{~F} \mathrm{NMR,}$ chemical shifts are reported vs. $\mathrm{CFCl}_{3}$ at $0 \mathrm{ppm}$ by adjusting the shift of hexafluorobenzene, used as an internal reference at $-164.9 \mathrm{ppm}$. Mass spectra were obtained on a Thermo Finnigan LTQ ion trap mass spectrometer. Elemental analysis was performed by Atlantic Microlab, Inc. Electrodes were purchased from $\mathrm{CH}$ Instruments.

The separators and membranes were used as received. Daramic 175 separators (175 $\mu \mathrm{m}$, porosity is $58 \%$, and mean pore size is $100 \mathrm{~nm}$ ) were donated by Daramic LLC (Charlotte, North Carolina). FAPQ 375 PP anion exchange membranes $(75 \mu \mathrm{m})$ were purchased from FumaTech Gmbh (St. Ingberg, Germany). Nafion 117 membranes $(183 \mu \mathrm{m})$ were purchased from lon power Inc. (New Castle, Deleware). All membranes or separators, used as received, were soaked in 0.5 $\mathrm{M} \mathrm{TEABF}{ }_{4} / \mathrm{ACN}$ for $24 \mathrm{~h}$ before employing them in $\mathrm{H}$-cell and flow cell experiments. All experiments were conducted in an argon atmosphere glovebox (MBraun, $\mathrm{O}_{2}<5 \mathrm{ppm}, \mathrm{H}_{2} \mathrm{O}<0.1$ ppm).

\section{Solubility}

The solubilities of MEEPT, MEEPT-BF 4 , and MEEV-TFSI ${ }_{2}$ in ACN, PC, DME, $0.5 \mathrm{M} \mathrm{TEABF}_{4}(\mathrm{ACN}$ and PC), and $0.5 \mathrm{M}$ TEATFSI (ACN, PC, and DME) were determined by a shake-flask method. Aliquots of test solvent (50 $-100 \mu \mathrm{L}$ ) were slowly added (around $10 \mathrm{~s}$ ) to each active material (80 - $110 \mathrm{mg}$ ), and suspensions were stirred between additions. The dilution process was stopped after complete dissolution of the solid, as determined by visual inspection. Then, a portion of saturated solution $(50-100 \mu \mathrm{L})$ was taken and weight of the aliquot was recorded to calculate the density of the solution. The calculated density was used to calculate the real volume of the 
samples. This process was done in triplicate to calculate the average molarity/solubility of the active materials.

\section{Cyclic Voltammetry}

CV experiments were conducted using a $\mathrm{CH}$ instruments $650 \mathrm{E}$ potentiostat. Glassy carbon (3 $\mathrm{mm}$ diameter) was employed as the working electrode, platinum wire as the counter electrode, and an un-fritted freshly anodized $\mathrm{Ag} / \mathrm{AgCl}$ wire as the reference electrode. Ferrocene was used as the internal reference in $6 \mathrm{~mL}$ solution, and half-wave redox potentials $\left(E_{1 / 2}\right)$ were reported with respect to ferrocene / ferrocenium $\left(\mathrm{Cp}_{2} \mathrm{Fe}^{0 /+}\right)$. 100\% solution resistance compensation / IR correction was applied. Half-wave redox potentials are reported as the average of the potential of the peaks for the forward and reverse waves. Peak current ratios $\left(\mathrm{i}_{\mathrm{p}, \mathrm{ox}} / \mathrm{i}_{\mathrm{p}, \text { red }}\right)$ were calculated by dividing the oxidation current by the reduction current. A scan rate of $100 \mathrm{mV} \mathrm{s}^{-1}$ was used in voltammograms that were analyzed to determine redox potential and peak current ratios. Diffusion coefficients were calculated by using the Randles-Sevcik equation at scan rates of 25 , $50,75,100,200,300,400$, and $500 \mathrm{mV} \mathrm{s}^{-1}$ using equation 1.

$$
i_{p}=0.4463 n F A c\left(\frac{n F D}{R T} v\right)^{0.5}
$$

where $\mathrm{i}_{\mathrm{p}}$ is the peak current $(\mathrm{A}), \mathrm{n}$ is the number of electrons transferred, $\mathrm{F}$ is the Faraday constant $\left(96485 \mathrm{C} \mathrm{mol}^{-1}\right), A$ is the electrode area $\left(\mathrm{cm}^{2}\right), \mathrm{c}$ is the concentration $\left(\mathrm{mol} \mathrm{cm}^{-3}\right), \mathrm{D}$ is the diffusion coefficient $\left(\mathrm{cm}^{2} \mathrm{~s}^{-1}\right), \mathrm{R}$ is the gas constant $\left(8.314 \mathrm{~J} \mathrm{~mol}^{-1} \mathrm{~K}^{-1}\right), \mathrm{T}$ is the absolute temperature $(\mathrm{K})$, and $\mathrm{v}$ is the scan rate $\left(\mathrm{V} \mathrm{s}^{-1}\right) .{ }^{44}$

\section{H Cell Testing}

For analysis of crossover using visual inspection, we used stationary $\mathrm{H}$-cells bridged by a series of membranes and separators. For the first measurements, we used direct visualization of crossover, assembling $\mathrm{H}$-cells and filling each side with electrolyte. One side contained the active material MEEPT at $25 \mathrm{mM}$ in $0.5 \mathrm{M} \mathrm{TEABF}_{4} / \mathrm{ACN}$. Photographs were recorded at $12 \mathrm{~h}$. Because the solutions are colorless, the oxidizing agent $\mathrm{NOBF}_{4}$ was added for visualization. Upon its addition, MEEPT is transformed into its radical cation salt, which is intensely colored, allowing for visual inspection.

For analysis of crossover using $\mathrm{CV}, \mathrm{H}$-cells were constructed in which the left side of the cell

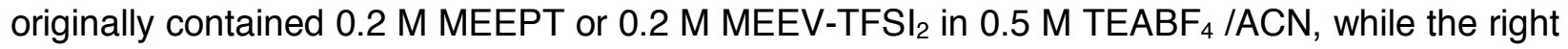
side originally contained electrolyte $\left(0.5 \mathrm{M} \mathrm{TEABF}_{4} / \mathrm{ACN}\right)$ only. Membranes were pre-soaked in electrolyte prior to $\mathrm{H}$-cell assembly. Cyclic voltammograms of solutions on both sides of the $\mathrm{H}$ cell were recorded at various times until $24 \mathrm{~h}$. For the CV analysis, $50 \mu \mathrm{L}$ aliquot was taken from both sides of the $\mathrm{H}$-cell and diluted in $5 \mathrm{~mL}$ of $0.5 \mathrm{M}$ TEABF $/ \mathrm{ACN}$.

\section{Flow Cell Cycling}

Small volume custom flow cells with interdigitated flow fields were used during redox flow cell cycling. ${ }^{29}$ The backing plates were made from polypropylene. Impregnated graphite was used to make the graphite flow fields (3.18 mm thick, product G347B, MWI Inc., Rochester, NY). Carbon papers (SGL 29 AA, $190 \pm 30 \mu$ m thickness, SGL group, Wiesbaden, Germany) were cut to 1.7 $\mathrm{cm} \times 1.5 \mathrm{~cm}$ One piece of carbon paper was layered on each side of the separator (Daramic 175, Daramic LLC) or membrane (FAPQ 375 PP, Fuma-Tech). The cells were sealed using custom gaskets cut from polytetrafluoroethylene gasket tape (Goretex) with an area of $2.55 \mathrm{~cm}^{2}$. All flow 
cells bodies were assembled in the air and then dried in the vacuum oven (room temperature, pressure $\sim-100 \mathrm{kPa}$ ) for $\sim 1 \mathrm{~h}$ before being transferred into an argon-filled glovebox (MBraun, $\mathrm{O}_{2}$ $<5$ ppm, $\left.\mathrm{H}_{2} \mathrm{O}<0.1 \mathrm{ppm}\right)$.

$10 \mathrm{~mL}$ Perfluoroalkoxyalkane (PFA) jars (Savillex) were used as electrolyte reservoirs, and a peristaltic pump (Masterflex L/S Series) was used to carry the electrolyte at a flow rate of $10 \mathrm{~mL}$ $\mathrm{min}^{-1}$. Norprene tubing (Masterflex) was used inside the pump head. PFA tubing (Swagelok) connected the reservoirs to the flow cell. Stainless steel compression fittings (Swagelok) were used to connect the Norprene and PFA tubing. All tubing inner diameter was $1.6 \mathrm{~mm}$.

0.5 $\mathrm{M} \mathrm{TEABF}_{4}$ in $\mathrm{ACN}_{\text {was }}$ used as the electrolyte for all the flow cell cycling in this study. For low concentration flow cells, two methods were used for preparing positive and negative electrolytes:

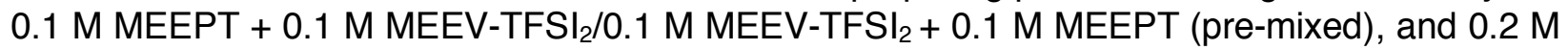
MEEPT/0.2 M MEEV-TFSI 2 (separated). The positive and negative sides of the cell were separated by one layer of Daramic 175, one-layer of FAPQ 375 PP, or two layers of FAPQ 375 $\mathrm{PP}$. For high concentration flow cells, the positive and negative electrolytes were prepared as 0.5 $\mathrm{M}$ MEEPT + 0.5 M MEEV-TFSI $/ 2$.0.5 M MEEV-TFSI $\mathrm{M}_{2}+0.5 \mathrm{M}^{\mathrm{MEEPT}}$ (Daramic 175 and FAPQ $375 \mathrm{PP}$ ) and $0.5 \mathrm{M}$ MEEPT/0.5 M MEEV-TFSI 2 (2 x FAPQ $375 \mathrm{PP}$ ). For high concentration flow cells, due to the volatility of ACN and long cycling periods, ACN was added occasionally in to maintain $10 \mathrm{~mL}$ total electrolyte volume in each reservoir, during which cell cycling was paused. To analyze the causes of capacity fade, two electrolyte solutions were re-balanced within the cell containing one or two layers FAPQ 375 PP, which was done by combining the two solutions, then dividing them in equal volumes, which were then used as each the negative and positive electrolyte when cycling was resumed.

\section{Supplemental Information Description}

The Supplemental Information contains cyclic voltammograms of the two active materials in a variety of electrolytes at varying sweep rates, solubility values, ionic conductivity values of various electrolytes, photographs of $\mathrm{H}$-cell crossover tests, cyclic voltammograms spectra of crossover tests, additional membrane impedance analysis and flow cell cycling, and post-mortem cycling crossover analysis.

\section{Acknowledgements}

The Odom and Brushett groups thank the National Science Foundation for a PFI:AIR-TT award (1701085) for funding of this project. KVG and BJN gratefully acknowledge financial support from the National Science Foundation Graduate Research Fellowship Program under Grant No. 1122374. Any opinions, findings, or recommendations expressed in this material are those of the authors and do not necessarily reflects the views of the National Science Foundation.

\section{Author Contributions}

ZL performed crossover, cyclic voltammetry, ionic conductivity measurements and fabricated and cycled flow cells. NHA, APK, and WLE synthesized the numerous batches of the active material

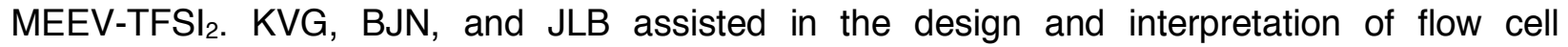
experiments. FRB, JL, and SAO were the team leads in project design and data interpretation. All authors contributed to the preparation of the manuscript. 


\section{Declaration of Interests}

The Odom group has various patent applications related to nonaqueous redox flow batteries under consideration with the US Patent and Trademark Office.

\section{References}

1. Sutherland, B. R., Charging up stationary energy storage. Joule 2019, 3, 1-3.

2. Weber, A. Z.; Mench, M. M.; Meyers, J. P.; Ross, P. N.; Gostick, J. T.; Liu, Q., Redox flow batteries: a review. J. Appl. Electrochem. 2011, 41, 1137.

3. Shin, S.-H.; Yun, S.-H.; Moon, S.-H., A review of current developments in non-aqueous redox flow batteries: characterization of their membranes for design perspective. RSC Adv. 2013, 3, 9095-9116.

4. $\quad$ Prifti, H.; Parasuraman, A.; Winardi, S.; Lim, T. M.; Skyllas-Kazacos, M., Membranes for Redox Flow Battery Applications. Membranes 2012, 2, 275-306.

5. Wang, W.; Luo, Q.; Li, B.; Wei, X.; Li, L.; Yang, Z., Recent Progress in Redox Flow Battery Research and Development. Adv. Funct. Mater. 2013, 23, 970-986.

6. Hsu, W. Y.; Gierke, T. D., Ion transport and clustering in Nafion perfluorinated membranes. Journal of Membr. Sci. 1983, 13, 307-326.

7. Grot, W. G. In Perfluorinated ion exchange polymers and their use in research and industry, Macromolecular Symposia, Wiley Online Library: 1994; pp 161-172.

8. Shi, Y.; Eze, C.; Xiong, B.; He, W.; Zhang, H.; Lim, T. M.; Ukil, A.; Zhao, J., Recent development of membrane for vanadium redox flow battery applications: A review. Appl. Energy 2019, 238, 202-224.

9. $\mathrm{Xi}$, J.; $\mathrm{Wu}, \mathrm{Z}$.; Qiu, X.; Chen, L., Nafion $/ \mathrm{SiO}_{2}$ hybrid membrane for vanadium redox flow battery. J. Power Sources 2007, 166, 531-536.

10. Sun, C.; Chen, J.; Zhang, H.; Han, X.; Luo, Q., Investigations on transfer of water and vanadium ions across Nafion membrane in an operating vanadium redox flow battery. J. Power Sources 2010, 195, 890-897.

11. Chae, I. S.; Luo, T.; Moon, G. H.; Ogieglo, W.; Kang, Y. S.; Wessling, M., Ultra-high proton/vanadium selectivity for hydrophobic polymer membranes with intrinsic nanopores for redox flow battery. Adv. Energy Mater. 2016, 6, 1600517.

12. Schwenzer, B.; Zhang, J.; Kim, S.; Li, L.; Liu, J.; Yang, Z., Membrane Development for Vanadium Redox Flow Batteries. ChemSusChem 2011, 4, 1388-1406.

13. Luo, T.; Abdu, S.; Wessling, M., Selectivity of ion exchange membranes: A review. J. Membr. Sci. 2018, 555, 429-454. 
14. Baran, M. J.; Braten, M. N.; Montoto, E. C.; Gossage, Z. T.; Ma, L.; Chénard, E.; Moore, J. S.; Rodríguez-López, J.; Helms, B. A., Designing Redox-Active Oligomers for Crossover-Free, Nonaqueous Redox-Flow Batteries with High Volumetric Energy Density. Chem. Mater. 2018, 30, 3861-3866.

15. Wei, X.; Pan, W.; Duan, W.; Hollas, A.; Yang, Z.; Li, B.; Nie, Z.; Liu, J.; Reed, D.; Wang, W.; Sprenkle, V., Materials and Systems for Organic Redox Flow Batteries: Status and Challenges. ACS Energy Lett. 2017, 2, 2187-2204.

16. Park, J. H.; Park, J. J.; Park, O. O.; Yang, J. H., Capacity Decay Mitigation by Asymmetric Positive/Negative Electrolyte Volumes in Vanadium Redox Flow Batteries. ChemSusChem 2016, 9, 3181-3187.

17. Milshtein, J. D.; Kaur, A. P.; Casselman, M. D.; Kowalski, J. A.; Modekrutti, S.; Zhang, P. L.; Attanayake, N. H.; Elliott, C. F.; Parkin, S. R.; Risko, C.; Brushett, F. R.; Odom, S. A., High Current Density, Long Duration Cycling of Soluble Organic Active Species for Non-aqueous Redox Flow Batteries. Energy Environ. Sci. 2016, 9, 3531-3543.

18. Liu, Y.; Goulet, M.-A.; Tong, L.; Liu, Y.; Ji, Y.; Wu, L.; Gordon, R. G.; Aziz, M. J.; Yang, Z.; $\mathrm{Xu}, \mathrm{T}$., A Long-Lifetime All-Organic Aqueous Flow Battery Utilizing TMAP-TEMPO Radical. Chem 2019, 5, 1861-1870.

19. Ji, Y.; Goulet, M.-A.; Pollack, D. A.; Kwabi, D. G.; Jin, S.; De Porcellinis, D.; Kerr, E. F.; Gordon, R. G.; Aziz, M. J., A Phosphonate-Functionalized Quinone Redox Flow Battery at NearNeutral pH with Record Capacity Retention Rate. Adv. Energy Mater. 2019, 9, 1900039.

20. Kwabi, D. G.; Lin, K.; Ji, Y.; Kerr, E. F.; Goulet, M.-A.; De Porcellinis, D.; Tabor, D. P.; Pollack, D. A.; Aspuru-Guzik, A.; Gordon, R. G., Alkaline quinone flow battery with long lifetime at $\mathrm{pH}$ 12. Joule 2018, 2, 1894-1906.

21. Wei, X.; Xu, W.; Vijayakumar, M.; Cosimbescu, L.; Liu, T.; Sprenkle, V.; Wang, W., TEMPO-Based Catholyte for High-Energy Density Nonaqueous Redox Flow Batteries. Adv. Mater. 2014, 26, 7649-7653.

22. Kwon, G.; Lee, K.; Lee, M. H.; Lee, B.; Lee, S.; Jung, S.-K.; Ku, K.; Kim, J.; Park, S. Y.; Kwon, J. E.; Kang, K., Bio-inspired Molecular Redesign of a Multi-redox Catholyte for High-Energy Non-aqueous Organic Redox Flow Batteries. Chem 2019, 5, 2642-2656.

23. Attanayake, N. H.; Kowalski, J. A.; Greco, K.; Casselman, M. D.; Milshtein, J. D.; Chapman, S. J.; Parkin, S. R.; Brushett, F. R.; Odom, S. A., Tailoring Two-Electron Donating Phenothiazines to Enable High Concentration Redox Electrolytes for Use in Nonaqueous Redox Flow Batteries. Chem. Mater. 2019, 31, 4353-4363.

24. Doris, S. E.; Ward, A. L.; Baskin, A.; Frischmann, P. D.; Gavvalapalli, N.; Chénard, E.; Sevov, C. S.; Prendergast, D.; Moore, J. S.; Helms, B. A., Macromolecular Design Strategies for Preventing Active-Material Crossover in Non-aqueous All-Organic Redox-Flow Batteries. Angew. Chem. Int. Ed. 2017, 56, 1595-1599. 
25. Leung, P.; Shah, A. A.; Sanz, L.; Flox, C.; Morante, J. R.; Xu, Q.; Mohamed, M. R.; Ponce de León, C.; Walsh, F. C., Recent developments in organic redox flow batteries: A critical review. J. Power Sources 2017, 360, 243-283.

26. Kowalski, J. A.; Su, L.; Milshtein, J. D.; Brushett, F. R., Recent advances in molecular engineering of redox active organic molecules for nonaqueous flow batteries. Curr. Opin. Chem. Eng. 2016, 13, 45-52.

27. Ding, Y.; Zhang, C.; Zhang, L.; Zhou, Y.; Yu, G., Molecular engineering of organic electroactive materials for redox flow batteries. Chem. Soc. Rev. 2018, 47, 69-103.

28. Attanayake, N. H.; Kowalski, J. A.; Greco, K. V.; Casselman, M. D.; Milshtein, J. D.; Chapman, S. J.; Parkin, S. R.; Brushett, F. R.; Odom, S. A., Tailoring Two-Electron-Donating Phenothiazines To Enable High-Concentration Redox Electrolytes for Use in Nonaqueous Redox Flow Batteries. Chem. Mater. 2019, 31, 4353-4363.

29. Milshtein, J. D.; Kaur, A. P.; Casselman, M. D.; Kowalski, J. A.; Modekrutti, S.; Zhang, P. L.; Harsha Attanayake, N.; Elliott, C. F.; Parkin, S. R.; Risko, C.; Brushett, F. R.; Odom, S. A., High current density, long duration cycling of soluble organic active species for non-aqueous redox flow batteries. Energy Environ. Sci. 2016, 9, 3531-3543.

30. Small, L. J.; Pratt, H. D.; Anderson, T. M., Crossover in Membranes for Aqueous Soluble Organic Redox Flow Batteries. J. Electrochem. Soc. 2019, 166, A2536-A2542.

31. Wei, X.; Xu, W.; Huang, J.; Zhang, L.; Walter, E.; Lawrence, C.; Vijayakumar, M.; Henderson, W. A.; Liu, T.; Cosimbescu, L.; Li, B.; Sprenkle, V.; Wang, W., Radical Compatibility with Nonaqueous Electrolytes and Its Impact on an All-Organic Redox Flow Battery. Angew. Chem. Int. Ed. 2015, 54, 8684-8687.

32. Duan, W.; Huang, J.; Kowalski, J. A.; Shkrob, I. A.; Vijayakumar, M.; Walter, E.; Pan, B.; Yang, Z.; Milshtein, J. D.; Li, B.; Liao, C.; Zhang, Z.; Wang, W.; Liu, J.; Moore, J. S.; Brushett, F. R.; Zhang, L.; Wei, X., "Wine-Dark Sea" in an Organic Flow Battery: Storing Negative Charge in 2,1,3-Benzothiadiazole Radicals Leads to Improved Cyclability. ACS Energy Lett. 2017, 2, 11561161.

33. Yan, Y.; Robinson, S. G.; Sigman, M. S.; Sanford, M. S., Mechanism-Based Design of a High-Potential Catholyte Enables a 3.2 V All-Organic Nonaqueous Redox Flow Battery. J. Am. Chem. Soc. 2019, 141, 15301-15306.

34. Vaid, T. P.; Sanford, M. S., An organic super-electron-donor as a high energy density negative electrolyte for nonaqueous flow batteries. Chem. Commun. 2019, 55, 11037-11040.

35. N. Harsha Attanayake, Z. L., Yilin Wang, Aman Preet Kaur, Giorgio Baggi,; Sean R. Parkin, J. K. M., Randy H. Ewoldt, James Landon,Susan A. Odom, Dual Function Organic Active Materials for Nonaqueous Redox Flow Batteries. Mater. Adv., manuscript accepted. DOI: 10.1039/D0MA0081H

36. Darling, R.; Gallagher, K.; Xie, W.; Su, L.; Brushett, F., Transport Property Requirements for Flow Battery Separators. J. Electrochem. Soc. 2016, 163, A5029-A5040. 
37. Muhuri, P. K.; Hazra, D. K., Density and Viscosity for Propylene Carbonate + 1,2Dimethoxyethane at 298.15, 308.15, and 318.15 K. J. Chem. Eng. Data 1994, 39, 375-377.

38. Aminabhavi, T. M.; Gopalakrishna, B., Density, Viscosity, Refractive Index, and Speed of Sound in Aqueous Mixtures of N,N-Dimethylformamide, Dimethyl Sulfoxide, N,NDimethylacetamide, Acetonitrile, Ethylene Glycol, Diethylene Glycol, 1,4-Dioxane, Tetrahydrofuran, 2-Methoxyethanol, and 2-Ethoxyethanol at 298.15 K. J. Chem. Eng. Data 1995, 40, 856-861.

39. Zheng, P.; Meng, X.; Wu, J.; Liu, Z., Density and Viscosity Measurements of Dimethoxymethane and 1,2-Dimethoxyethane from $243 \mathrm{~K}$ to $373 \mathrm{~K}$ up to $20 \mathrm{MPa}$. Int. J. Thermophys. 2008, 29, 1244-1256.

40. Xi, J.; Wu, Z.; Teng, X.; Zhao, Y.; Chen, L.; Qiu, X., Self-assembled polyelectrolyte multilayer modified Nafion membrane with suppressed vanadium ion crossover for vanadium redox flow batteries. J. Mater. Chem. 2008, 18, 1232-1238.

41. Small, L. J.; Pratt III, H. D.; Staiger, C. L.; Anderson, T. M., MetILs3: A Strategy for High Density Energy Storage Using Redox-Active Ionic Liquids. Adv. Sustain. Syst. 2017, 1, 1700066.

42. Darling, R. M.; Weber, A. Z.; Tucker, M. C.; Perry, M. L., The influence of electric field on crossover in redox-flow batteries. J. Electrochem. Soc. 2015, 163, A5014.

43. Hu, J.; Wang, P.; Lin, Y.; Yang, S.; Song, B.; Wang, Q., Dual responsive supramolecular amphiphiles: guest molecules dictate the architecture of pyridinium-tailored anthracene assemblies. Org. Biomol. Chem.2014, 12, 4820-4823.

44. Compton, R. G.; Banks, C. E., In Understanding Voltammetry, 2nd ed.; Imperial College Press: London, 2011. 